\title{
SAND2000-02360
}

\section{CONSTITUTIVE MODELING OF VISCOPLASTIC DAMAGE IN SOLDER MATERIAL*}

\author{
Y. WEI and C. L. CHOW \\ Department of Mechanical Engineering \\ University of Michigan-Dearborn \\ Dearborm, Michigan 48128, USA
}

\author{
M.K. NEILSEN and H.E. FANG \\ Sandia National Laboratories, \\ Albuquerque, NM 87185, USA
}

\begin{abstract}
This paper presents a constitutive modeling of viscoplastic damage in $63 \mathrm{Sn}-37 \mathrm{~Pb}$ solder material taking into account the effects of micro-structural change in grain coarsening. Based on the theory of damage mechanics, a two-scalar damage model is developed by introducing the damage variables and the free energy equivalence principle. An inelastic potential function based on the concept of inelastic damage energy release rate is proposed and used to derive an inelastic damage evolution equation

The validation of the model is carried out for the viscoplastic material by predicting monotonic tensile behavior and tensile creep curves at different temperatures. The softening behavior of the material under monotonic tension loading can be characterized with the model. The results demonstrate adequately the validity of the proposed viscoplastic constitutive modeling for the solder material.
\end{abstract}

\section{Introduction}

The $\mathrm{Pb}-\mathrm{Sn}$ eutectic alloy is widely used as a joining material in the electronic industry. In this application the solder acts as both electrical and mechanical connection within and among different packaging levels in an electronic device. Advances in packaging technologies driven by the desire for miniaturization and increased circuit speed result in severe operating conditions for the solder joint. thus causing solder joint reliability concerns. Solder joints are usually subjected to the operating temperature as high as 0.5 to 0.8 times its melting temperature $\left(\mathrm{T}_{\mathrm{m}}\right)$. It is well known that the behavior of $\mathrm{Pb}-\mathrm{Sn}$

- This work was supported by the United States Department of Energy under Contract DE-AC04-94AL85000. Sandia is a multiprogram laboratory operated by Sandia Corporation, a Lockheed Martin Company, for the United States Department of Energy. 
eutectic solder material is highly rate sensitive and time dependent. For a reliability analysis, knowledge on the mechanical behavior of solder joints under thermomechanical loading is necessary. In past decade, many researchers have studied constitutive modeling and reliability of solder joints (Solomon, 1986, Busso, et al., 1994, McDowell, et al., 1994, Shine, et al., 1994, Frear, et al., 1997, Lau, et al., 1997 and Shi, et al. 1999). However, the previous work focuses on either the experimental results or the conventional analytical approaches based on the assumption that all materials are perfect or defects-free during a loading process. There are only a few investigations examining the effects of damage on the behavior of solder material (Basaran, et al., 1998, Wei, et al., 1999 and Qian, et al., 1999).

The primary objective of this paper is to present a damage model which takes into account the effects of damage accumulation on mechanical behavior of the solder material. The methodology is based on the theory of Damage Mechanics. The theory enables a macroscopic description of material deterioration and stiffness degradation due to the presence of micro-defects that initiate, coalescence and grow under load. The accumulation of damage is manifested as a reduction in the effective load bearing area of solder joints, causing eventually macro-crack initiation and failure in a solder material. A two-scalar damage model is for the first instance introduced to quantify the degree of damage. Then the model is applied to characterize the effects of damage on mechanical behavior of $63 \mathrm{Sn}-37 \mathrm{~Pb}$ solder material, including its softening behavior. The validation of the damage mode is carried out by comparing the predicted and measured results.

\section{Damage Variables}

Based on the concept of damage mechanics, the effective stress $\bar{\sigma}$ is defined as

$$
\bar{\sigma}=\mathbf{M}(\mathrm{D}): \sigma
$$

where $\sigma$ is the true (Cauchy) stress tensor, $M(D)$ is the damage effect tensor and $D$ is the damage variable. The damage variable, known as an internal state variable, is introduced to characterize the gradual deterioration of the material. The effective stress provides an essential mechanism by which the damage variable is coupled with constitutive models through the damage effect tensor. Therefore, a proper definition of $\mathbf{M}$ in Equation ( 1 ) is important. The damage effect tensor may be established with two scalar variables $D$ and $\mu$ as proposed by Chow, et al., 1999

$$
\mathrm{M}=\frac{1}{1-\mathrm{D}}\left[\begin{array}{cccccc}
1 & \mu & \mu & 0 & 0 & 0 \\
\mu & 1 & \mu & 0 & 0 & 0 \\
\mu & \mu & 1 & 0 & 0 & 0 \\
0 & 0 & 0 & 1-\mu & 0 & 0 \\
0 & 0 & 0 & 0 & 1-\mu & 0 \\
0 & 0 & 0 & 0 & 0 & 1-\mu
\end{array}\right]
$$




\section{DISCLAIMER}

This report was prepared as an account of work sponsored by an agency of the United States Government. Neither the United States Government nor any agency thereof, nor any of their employees, make any warranty, express or implied, or assumes any legal liability or responsibility for the accuracy, completeness, or usefulness of any information, apparatus, product, or process disclosed, or represents that its use would not infringe privately owned rights. Reference herein to any specific commercial product, process, or service by trade name, trademark, manufacturer, or otherwise does not necessarily constitute or imply its endorsement, recommendation, or favoring by the United States Government or any agency thereof. The views and opinions of authors expressed herein do not necessarily state or reflect those of the United States Government or any agency thereof. 


\section{DISCLAIMER}

Portions of this document may be illegible in electronic image products. Images are produced from the best available original document. 
where $D$ and $\mu$ are two independent components of damage tensor $D$. Obviously, this damage effect tensor reduces to the form $M=V /(1-D)$ when the value of $\mu$ is zero. This corresponds to a special case of isotropic damage for which the value of Poisson's ratio remains constant under load.

In order to consider the effects of damage, the free energy equivalence principle is postulated as: the free energy for a damaged material may be expressed similar in form as a virgin/as-received material except that the true (Cauchy) stress is replaced by the effective stress. Therefore, the free energy for a damaged solder material is postulated as

$$
\begin{aligned}
\Psi & =\frac{1}{2} \bar{\sigma}^{T}: \mathrm{C}_{0}^{-1}: \bar{\sigma}+\frac{3}{4} C_{k 0}^{-1} \mathrm{X}^{T}: \mathrm{X} \\
& =\frac{1}{2} \sigma^{T}: \mathrm{M}^{T}: \mathrm{C}_{0}^{-1}: \mathrm{M}: \sigma+\frac{3}{4} C_{k 0}^{-1} \mathrm{X}^{T}: \mathrm{X} \\
& =\frac{1}{2} \sigma^{T}: \mathrm{C}^{-1}: \sigma+\frac{3}{4} C_{k 0}^{-1} \mathrm{X}^{T}: \mathrm{X}
\end{aligned}
$$

where $\mathrm{X}$ is the back stress tensor, $\mathrm{C}_{0}^{-1}$ is the fourth order elastic tensor without damage. $C_{k 0}^{-1}$ is the material parameter for kinematic hardening, and $\mathrm{C}^{-1}$ is the effective elastic tensor for a damaged material derived as :(Chow, 1999)

$$
\mathrm{C}^{-1}=\mathbf{M}^{T}: \mathbf{C}_{0}^{-1}: \mathrm{M}=\frac{I}{E}\left[\begin{array}{rrrrrr}
I & -v & -v & 0 & 0 & 0 \\
-v & l & -v & 0 & 0 & 0 \\
-v & -v & l & 0 & 0 & 0 \\
0 & 0 & 0 & 2(1+v) & 0 & 0 \\
0 & 0 & 0 & 0 & 2(1+v) & 0 \\
0 & 0 & 0 & 0 & 0 & 2(1+v)
\end{array}\right]
$$

$E$ and $v$ in Equation (4) are the Young's modulus and the Poisson's ratio for damaged materials expressed in terms of the damage variables $\mathrm{D}$ and $\mu$ as

$$
E=\frac{E_{0}(1-D)^{2}}{I-4 v_{0} \mu+2\left(1-v_{0}\right) \mu^{2}} \quad v=\frac{v_{0}-2\left(1-v_{0}\right) \mu-\left(I-3 v_{0}\right) \mu^{2}}{1-4 v_{0} \mu+2\left(1-v_{0}\right) \mu^{2}}
$$

$\mathrm{E}_{0}$ and $\mu_{0}$ are the Young's modulus and the Poisson's ratio for undamaged or as-received material.

With the theory of irreversible thermodynamics, the damage energy release rates corresponding to the damage variables $\mathrm{D}$ and $\mu$ are defined with the free energy in Equation (3) as 


$$
\begin{aligned}
& Y_{D}=-\frac{\partial \Psi}{\partial D}=-\frac{1}{1-D} \sigma^{T}: \mathbf{C}^{-1}: \sigma \\
& Y_{\mu}=-\frac{\partial \Psi}{\partial \mu}=-\frac{1}{1-D} \sigma^{T}: \mathrm{Z}: \sigma
\end{aligned}
$$

where

$$
\begin{aligned}
& \mathrm{Z}=\frac{1}{E_{0}(1-D)}\left[\begin{array}{cccccc}
z_{1} & z_{2} & z_{2} & 0 & 0 & 0 \\
z_{2} & z_{1} & z_{2} & 0 & 0 & 0 \\
z_{2} & z_{2} & z_{1} & 0 & 0 & 0 \\
0 & 0 & 0 & 2\left(z_{1}-z_{2}\right) & 0 & 0 \\
0 & 0 & 0 & 0 & 2\left(z_{1}-z_{2}\right) & 0 \\
0 & 0 & 0 & 0 & 0 & 2\left(z_{1}-z_{2}\right)
\end{array}\right] \\
& z_{1}=2 \mu\left(1-v_{0}\right)-2 v_{0}
\end{aligned}
$$

In order to formulate deformation and damage evolution equations, an inelastic dissipation potential function $\phi$ is postulated for solder material to consist of two independent processes, i.e. a deformation process and a damaging process. Accordingly, the potential may be expressed as

$$
\phi=\phi^{i n}(\sigma, \mathbf{X})+\phi^{d}\left(Y_{i n d}\right)
$$

where $Y_{\text {ind, }}$, the equivalent inelastic damage energy release rate, is defined as

$$
Y_{\text {ind }}=\left[\frac{1}{2}\left(Y_{D}^{2}+\gamma Y_{\mu}^{2}\right)\right]^{1 / 2}
$$

$Y_{D}$ and $Y_{\mu}$ are the thermodynamic conjugate forces of the inelastic damage variables $D$ and $\mu$ in Equations (6) and (7). The inelastic damage part of the dissipation potential is postulated as

$$
\phi^{d}=\frac{Y_{h}}{b_{1}+1}\left(\frac{Y_{i n d}}{Y_{h}}\right)^{b_{1}+1}
$$

where $b_{1}$ is a material constant, and $Y_{h}$ is the inelastic damage hardening variable. Therefore, the inelastic damage evolution equations can be derived from Equation (9) as 


$$
\dot{D}=-i_{\text {in }} \frac{\partial \dot{\phi}}{\partial Y_{D}}=-\dot{w} \frac{Y_{D}}{2 Y_{\text {ind }}} \quad \dot{\mu}=-\lambda_{\text {in }} \frac{\partial o}{\partial Y_{\mu}}=-\dot{w} \frac{\gamma Y_{u}}{2 Y_{\text {ind }}}
$$

where $\dot{w}$, the overall inelastic damage rate, is defined as:

$$
\dot{w}=\lambda_{\text {in }} \frac{d \phi^{d}}{d Y_{\text {ind }}}=\lambda_{\text {in }}\left(\frac{Y_{\text {ind }}}{Y_{h}}\right)^{b_{1}}
$$

$\lambda_{\text {in }}$ is a multiplier, which is related to inelastic deformation to be described in the next section. The inelastic damage hardening variable $Y_{h}$ may be expressed in terms of the overall inelastic damage $w$ and the absolute temperature $T$ as

$$
Y_{h}(w, T)=Y_{0} e^{\left(b_{2} n+\frac{b_{n}}{r}\right)}
$$

where $Y_{0}, b_{2}$ and $b_{3}$ are material constants. The temperature effects on the inelastic damage evolution in equation (13) are included through the multiplier $\lambda_{\mathrm{m}}$ and the damage hardening variable $Y_{b}$.

\section{Constitutive Equations}

The damage coupled elastic constitutive equation is derived with the free energy in Equation (3) as:

$$
\varepsilon^{e}=\frac{\partial \Psi}{\partial \sigma}=\mathrm{C}^{-1}: \sigma \quad \sigma=\mathrm{C}: \varepsilon^{e}
$$

where $\varepsilon^{e}$ is the elastic strain. The kinematic hardening equation is derived from the free energy in Equation (3) as:

$$
\alpha_{k}=\frac{\partial \Psi}{\partial \mathrm{X}}=\frac{3}{2} C_{k 0}^{-1} \mathrm{X} \quad \mathrm{X}=\frac{2}{3} C_{k 0} \alpha_{k}
$$

where $\alpha_{k}$ is the back strain.

For inelastic deformation, the dissipation potential is written for the eutectic material as

$$
\phi^{i n}=J_{2}(\mathbf{S}-\mathbf{X})
$$

where $\mathrm{J}_{2}$ is a second invariant of the stress difference and defined as 


$$
J_{2}=\left\{\frac{3}{2}(\mathrm{~S}-\mathrm{X})^{\tau}:(\mathrm{S}-\mathrm{X})\right\}^{\frac{1}{2}}
$$

$\mathbf{S}$ is the deviatoric stress. Therefore, the inelastic strain rate can be expressed as

$$
\dot{\varepsilon}^{i n}=\lambda_{i n} \frac{\partial \phi}{\partial \sigma}=\lambda_{i n} \frac{\partial \phi^{i n}}{\partial \sigma}=\lambda_{i n} \frac{3}{2} \frac{S-X}{J_{2}}
$$

The multiplier $\lambda_{\text {in }}$ is equal to the equivalent inelastic strain rate $\dot{p}^{\text {in }}$ that may be expressed as (Frear, et al., 1997 and Wei, et al., 1999)

$$
\lambda_{\text {in }}=\dot{p}^{i n}=\frac{1-\mu}{1-D} f \exp \left(\frac{-Q}{R T}\right)\left(\frac{\lambda_{0}}{\lambda}\right)^{p} \sinh ^{m}\left(\frac{1-\mu}{1-D} \frac{J_{2}}{\alpha(c+\hat{c})}\right)
$$

where $f, p, m$ and $Q$ are material parameters, $R$ is the gas constant, $T$ is the absolute temperature, $\lambda$ is the current grain/phase size, $\lambda_{0}$ is the initial grain/phase size, $\alpha$ is a scalar function of the absolute temperature, $c$ and $\bar{c}$ are state variables.

The total strain is defined as

$$
\varepsilon=\varepsilon^{e}+\varepsilon^{i n}
$$

It is worthy noting that the effects of kinematic hardening, grain/phase size coarsening and damage accumulation are taken into account in Equation (20). The back strain tensor coupled with inelastic damage can be expressed as

$$
\dot{\alpha}_{k}=\frac{(1-D)^{2}}{(1-\mu)^{2}}\left\{\dot{\varepsilon}^{i n}-C_{k 0}\left(A_{5} \dot{p}^{i n}+A_{6}\right) \alpha_{k} \sqrt{\frac{2}{3} \alpha_{k}^{T}: \alpha_{k}}\right\}
$$

where $A_{5}$ and $A_{6}$ are material constants. The scalar state variable $c$, known as deformation hardening variable, is given by

$$
\dot{c}=A_{1} \dot{p}^{\dot{i n}}-\left(A_{2} \dot{p}^{\text {in }}+A_{3}\right)\left(c-c_{0}\right)^{2}
$$

where $c_{0}, A_{1}, A_{2}$ and $A_{3}$ are material parameters. The State variable $\hat{c}$ is related to the grain/phase size $\lambda$ by

$$
\hat{c}=A_{7}\left(\frac{\lambda_{0}}{\lambda}\right)^{\lambda_{s}}
$$

where $A_{7}$ and $A_{8}$ are positive material parameters. The evolution of the grain/phase size for $63 \mathrm{Sn}-37 \mathrm{~Pb}$ is given with experimental tests by 


$$
\lambda=\lambda_{0}+\left\{\left[4.1 \times 10^{-5} e^{-11023 / T}+15.6 \times 10^{-8} e^{-3123 / T} \dot{p}^{2 n}\right] t\right\}^{0256}
$$

where $t$ is the time.

\section{Applications}

Several monotonic tension and tensile creep tests have been designed for the determination of material parameters in the proposed model. The monotonic tension tests were carried out at three temperatures $\left(25^{\circ} \mathrm{C}, 75^{\circ} \mathrm{C}\right.$ and $\left.100^{\circ} \mathrm{C}\right)$ under different strain rates $\left(10^{-5} / \mathrm{s}\right.$ and $\left.10^{-1} / \mathrm{s}\right)$ by means of the strain control approach. The tensile creep tests were carried out at three temperatures $\left(25^{\circ} \mathrm{C}, 75^{\circ} \mathrm{C}\right.$ and $\left.100^{\circ} \mathrm{C}\right)$ under applied stress $0.6 \mathrm{ksi}$ by the load control approach. From our experimental observation on tension/creep tests, the measured damage values are very small, i.e. less than 0.02 for both $\mathrm{D}$ and $\mu$, when the total strain applied is less than $3 \%$. It is therefore reasonable to assume that the material degradation or damage can be considered negligible below the total strain of $3 \%$ and all the viscoplastic parameters can be determined without the damage consideration. The nonlinear least squares fit to the experimental data (less than $3 \%$ strain) was obtained using the Levenburg-Marquardt Algorithm (More, 1978). The measurement for Young s modulus and Poisson's ratio were carried out at certain strain intervals until final rupture of specimens. Accordingly, the damage parameters in the model were determined with the measured data. The material parameters determined for the $63 \mathrm{Sn}-37 \mathrm{~Pb}$ solder material are summarized in Table 1. The predicted results are shown in Fig.1 for monotonic tension and in Fig. 2 for tensile creep.

The damage model was applied to predict the monotonic tension behavior at true strain rate $10^{-4} / \mathrm{s}$ under three different temperatures, namely $25^{\circ} \mathrm{C}, 75^{\circ} \mathrm{C}$ and $100^{\circ} \mathrm{C}$. The predicted results are compared with test data as shown in Fig.3. The softening behavior of $63 \mathrm{Sn}-37 \mathrm{~Pb}$ solder material is observed from experimental tests and can be successfully characterized with the damage-coupled constitutive equations.

The uniaxial tensile creep is considered in this study to illustrate the potential applications of the proposed model. The applied stress is $4.14 \mathrm{MPa}$ at three different temperatures, $25^{\circ} \mathrm{C}, 75^{\circ} \mathrm{C}$ and $100^{\circ} \mathrm{C}$ respectively, under load control approach. Figure 4 shows a satisfactory comparison of the predicted creep curves with the test results.

\section{Conclusions}

A damage-coupled constitutive model is proposed with the theory of damage mechanics. The model was applied to predict the tensile behavior of the $63 \mathrm{Sn}-37 \mathrm{~Pb}$ solder material under several different strain rates and the tensile creep curves under different stress levels and temperatures. The softening behavior of the material under monotonic tension load was observed experimentally and can be adequately characterized with the proposed model. An excellent agreement of the predictions with experimental data is achieved. 


\section{References}

Basaran, C. and Yan. C.Y. (1998) A thermodynamic framework for damage mechanics of solder joints. Joumal of Electronic Packaging 120, 379-384.

Busso, E. P., Kitano, M. and Kumazawa. T. (1994) Modeling complex inelastic deformation processes in IC packages' solder joints, Joumal of Electronic Packaging 116, 6-15.

Chow, C.L and Wei, Y. (1999) Constitutive modeling of material damage for fatigue failure prediction. Intemational Joumal of Damage Mechanics 8, 355-375.

Frear, D. R.. Burcheth. S. N., Neilsen. M. K. and Stephens, J. J. (1997) Microstructurally based finite element simulation of solder joint behaviour, Soldering \& Surface Mount Technology 2.39-42.

Liu. J. H. and Pao, Y. H. (1997) Solder Joint Reliabiling of BGA, CSP. Flip Chip, and Fine Pitch SMT Assemblies, McGraw-Hill.

More, J.J. (1978) The Levenburg-Marquardt algorithm: implementation and theory, Lecture Notes in Mathematics 630 , edited by Watson. G.A., Springer-Verlag.

McDowell. D. L. Miller, M. P. and Brooks. D. C. (1994) A unified creep-plasticity theory for solder alloys. Fatigue of Electronic Materials. ASTM STP 1153, $42-59$.

Qian, Z. Ren. W. and Liu. S. (1999) A damage coupling framework of unified viscoplasticity for the fatigue of solder alloys. Journal of Electronic Packaging 121. 162-168.

Shi, X.Q., Zhou. W.. Pang. H.L.J. and Wang. Z.P. (1999) Effect of temperature and strain rate on mechanical properties of $63 \mathrm{Sn} / 37 \mathrm{~Pb}$ solder alloy, Joumal of Electronic Packaging 121. 179-185.

Shine. M. C. and Fox, L R. (1994) Fatigue of solder joints in surface mount devices, Low Cycle Fatigue. ASTM STP 942, 588-610.

Solomon, H. D. (1986) Creep, strain rate sensitivity and low cycle fatigue of $60 / 40$ solder. Brasing and Soldering 11.68-75.

Wei. Y.. Chow. C.L. Fang. H.E. and Neilsen. M.K. (1999) Characteristics of creep damage for 60Sn-40Pb solder material. ASME 99-IMECE/EEP-15. 
TABLE I 63Sn-37Pb solder material parameters

\begin{tabular}{|c|c|c|c|}
\hline Temperature $\left({ }^{\circ} \mathrm{C}\right)$ & 25 & 75 & 100 \\
\hline Temperature $\left({ }^{\circ} \mathrm{K}\right)$ & 298 & 348 & 373 \\
\hline Poisson's ratio & 0.4 & 0.4 & 0.4 \\
\hline Young's modulus (GPa) & 33.26 & 33.26 & 33.26 \\
\hline$A_{1}(\mathrm{MP})$ & $0.00 \mathrm{E}+00$ & $000 \mathrm{E} \div 00$ & $000 \mathrm{E}+00$ \\
\hline$A_{2}(1 / \mathrm{MPa})$ & $0.00 \mathrm{E}+00$ & $0.00 \mathrm{E}+00$ & $0.00 E+00$ \\
\hline$A_{3}(1 / \mathrm{MPa}-\mathrm{sec})$ & $0.00 \mathrm{E}+00$ & $000 \mathrm{E}+00$ & $000 \mathrm{E}+00$ \\
\hline $\mathrm{C}_{\mathrm{LO}}(\mathrm{GPa})$ & 28.15 & 22.08 & 19.32 \\
\hline$A_{5}(1 / \mathrm{MPa})$ & 44.95 & 103.0 & 153.7 \\
\hline$A_{6} \quad(1 / \mathrm{MPa}-\mathrm{sec})$ & $8.42 \mathrm{E}-03$ & $595 E-02$ & 0.2 \\
\hline$A_{7}(\mathrm{MPa})$ & 5.66 & 5.66 & 5.66 \\
\hline$A_{s}$ & 0.5 & 0.5 & 0.5 \\
\hline Flow rate $f(1 / \mathrm{sec})$ & $1.802 \mathrm{E}+06$ & $1.802 \mathrm{E}+06$ & $1.802 \mathrm{E}+06$ \\
\hline Sinh exponent $\mathrm{m}$ & 3.04 & 3.04 & 3.04 \\
\hline Growth exponentp & 3.00 & 300 & 3.00 \\
\hline Flow stress $\mathrm{C}_{0}(\mathrm{MPa})$ & 2.83 & 2.83 & 2.83 \\
\hline Phase size $\lambda_{0} \quad(\mathrm{~mm})$ & $2.257 \mathrm{E}-03$ & $2.37 \mathrm{E}-03$ & $2.257 \mathrm{E}-03$ \\
\hline Activation energy $Q(\mathrm{ca} / \mathrm{mol})$ & $1.376 \mathrm{E}+4$ & $1.376 \mathrm{E}+4$ & $1.376 \mathrm{E}+4$ \\
\hline Gas constant $R$ (cal/mol-K) & 1.987 & 1.987 & 1.987 \\
\hline Damage constant $b_{1}$ & 0.4 & 0.4 & 0.4 \\
\hline Damage constant $b_{2}$ & 5.0 & 5.0 & 5.0 \\
\hline Damage constant $b_{3}(1 / \mathrm{K})$ & $3.3+E+03$ & $3.34 E=03$ & $3.3+\mathrm{E}+03$ \\
\hline Damage constant $y$ & -0.2 & -0.2 & -0.2 \\
\hline Damage constant $Y_{0}(\mathrm{MPa})$ & 3.77E-08 & $3.77 \mathrm{E}-08$ & $3.77 \mathrm{E}-08$ \\
\hline
\end{tabular}




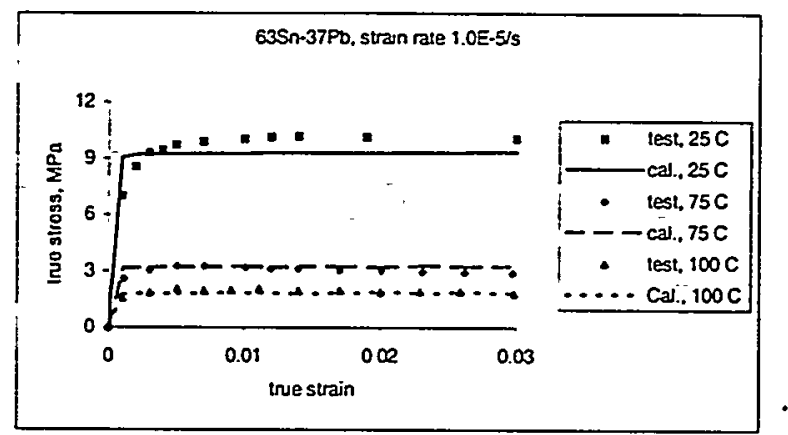

Figure 1a. Monotonic tension behavior at strain rate $10 \% / \mathrm{s}$

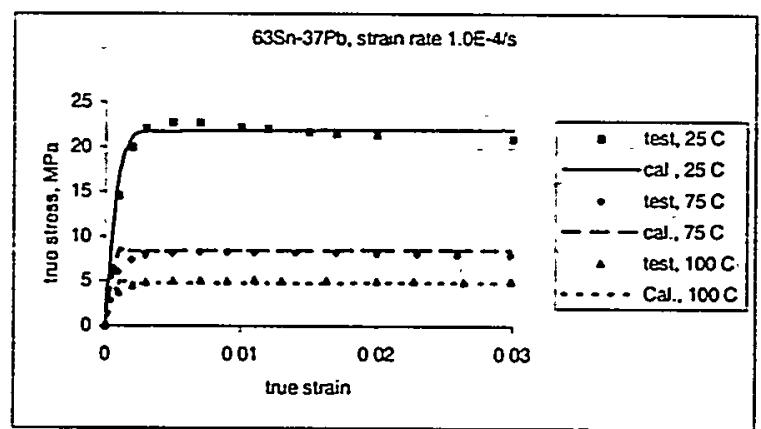

Figure Ib. Monotonic tension behavior at strain rate $10^{-1 / 5}$

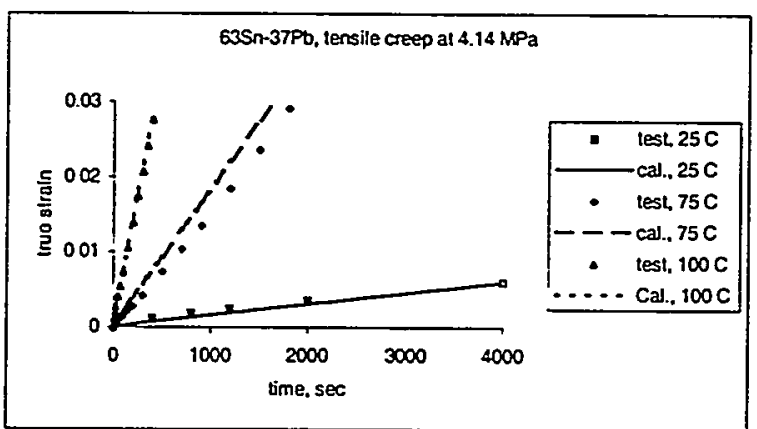

Figure 2. Tensile creep behavior at applied stress 4.14 MPa 


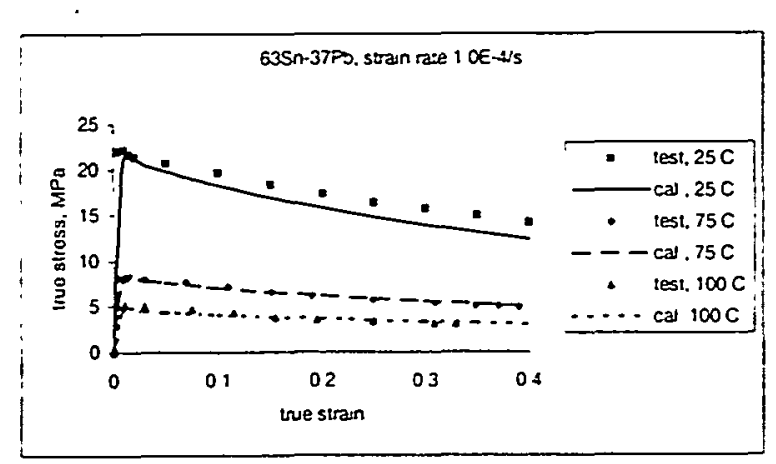

Figure 3. Softening behavior under monotonic tension at strain rate $10^{-1 / 5}$

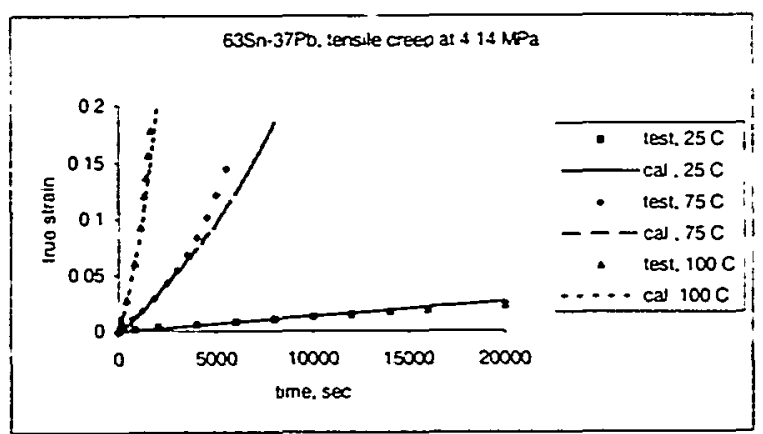

Figure 4. Prediction on tensile creep behasior at applied stress $4.14 \mathrm{MPa}$ 